\title{
Poaceae em uma planície de inundação no Brasil: listagem florística e novas ocorrências ${ }^{1}$
}

\author{
Kazue Kawakita $^{2,4}$, Rodrigo S. Rodrigues ${ }^{3}$ e Tarciso S. Filgueiras ${ }^{3}$
}

Recebido: 13.10.2015; aceito: 22.03.2016

\begin{abstract}
Poaceae in a Brazilian floodplain: floristic checklist and new occurrences). This study aims to characterize the grass flora of the Upper Paraná River Floodplain (PIAP) and its environs, located at $22^{\circ} 38^{\prime}-22^{\circ} 57^{\prime} \mathrm{S}$ and $53^{\circ} 05^{\prime}-53^{\circ} 36^{\prime} \mathrm{W}$, between the States of Paraná and Mato Grosso do Sul. We analyzed 916 botanical collections obtained from herbaria and fieldwork from 1988 to 2015 . The occurrence of 50 genera and 94 species was confirmed, of which $68.08 \%$ are native and $31.92 \%$ are naturalized. Panicoideae is the most representative subfamily, encompassing $68.08 \%$ of the species, followed by Chloridoideae (12.24\%) and Bambusoideae (11.22\%), whereas Oryzoideae, Arundinoideae and Pooideae represent less than $10 \%$ of the species. Most species are perennial $(80.85 \%)$, herbaceous $(77.66 \%)$ or arbustive $(12.77 \%)$, terrestrial $(42.55 \%)$, or from boggy areas (37.24\%). Seven species represent new records for the State of Mato Grosso do Sul, and seven for the State of Paraná.
\end{abstract}

Keywords: Gramineae, inventory, lowland, riparian vegetation

RESUMO - (Poaceae em uma planície de inundação no Brasil: listagem florística e novas ocorrências). O presente estudo objetiva caracterizar as Poaceae da Planície de Inundação do Alto Rio Paraná (PIAP) e seu entorno, localizada a $22^{\circ} 38^{\prime}-22^{\circ} 57^{\prime} \mathrm{S}$ e $53^{\circ} 05^{\prime}-53^{\circ} 36^{\prime} \mathrm{O}$, entre os Estados do Paraná e Mato Grosso do Sul. Foram analisadas 916 exsicatas provenientes de coleções de herbário ou obtidas em campo entre 1988 e 2015. Como resultado, registra-se a ocorrência de 50 gêneros e 94 espécies, sendo $68,08 \%$ nativas e $31,92 \%$ naturalizadas. Panicoideae é a maior subfamília, com $68,08 \%$ das espécies, seguida de Chloridoideae (12,24\%) e Bambusoideae (11,22\%), ao passo que Oryzoideae, Arundinoideae e Pooideae representam menos de $10 \%$ das espécies. A maioria das espécies é perene $(80,85 \%)$, porte herbáceo $(77,66 \%)$ ou arbustivo (12,77\%), terrestre $(42,55 \%)$ ou palustre $(37,24 \%)$. Sete espécies representam novos registros para o Mato Grosso do Sul e sete para o Paraná. Palavras-chave: Gramineae, inventário, várzea, vegetação ripária

\section{Introdução}

Poaceae é uma das maiores famílias dentre as Angiospermas e abrange espécies de importância fundamental, tanto como fonte de alimento para a humanidade e seus animais domésticos, quanto sob o ponto de vista ecológico. Ocorrem em praticamente todos os ecossistemas do planeta, tais como campos, banhados, desertos, florestas, planícies, montanhas e ambientes aquáticos, marinhos e de água doce (Alcântara \& Bufarah 1982, Chase 1991, Watson \& Dallwitz 1992, Boldrini et al. 2005, Judd et al. 2009).

Atualmente são citados 225 gêneros e 1.486 espécies de Poaceae para a flora do Brasil, sendo 88 gêneros e 291 espécies registrados para o Estado do Mato Grosso do Sul e 113 gêneros e 475 espécies para o Estado do Paraná (Filgueiras et al. 2015). Segundo estes autores, espécies dessa família distribuem-se por todos os biomas brasileiros, sendo a Mata Atlântica um dos mais ricos em número de gêneros (182) e de espécies (896).

A Planície de Inundação do Alto Rio Paraná (PIAP) localiza-se na divisa entre os Estados do Mato Grosso do Sul e Paraná. A vegetação existente na área é reflexo das cheias sazonais, das alterações promovidas pela construção das barragens hidrelétricas a montante, do processo de ocupação e do uso do solo no passado em decorrência da expansão da cafeicultura paranaense e

1. Parte da Tese de Doutorado da primeira Autora

2. Universidade Estadual de Maringá, Nupélia, Avenida Colombo, 5.790, bloco G-80, 87020-900 Maringá, PR, Brasil

3. Instituto de Botânica, Programa de Pós-graduação em Biodiversidade Vegetal e Meio Ambiente, Núcleo de Pesquisa Curadoria do Herbário SP, Avenida Miguel Stéfano, 3.687, 04301-902 São Paulo, SP, Brasil

4. Autor para correspondência: kazue@nupelia.uem.br 
das pastagens sul-matogrossenses (Campos \& Souza 1997, Campos 2004, Hayakawa et al. 2010). Outros aspectos importantes que interferem nas características da vegetação local são a drenagem das áreas úmidas (brejos), que tem ocorrido na várzea do Rio Paraná (Corradini 2006, UEM, 2015), o fogo, a extração de argila e a competição com espécies introduzidas e invasoras. Todos estes fatores, isolados ou em conjunto, são considerados ameaças que interferem na dinâmica natural das espécies nativas e podem levá-las à extinção local (Martinelli \& Moraes 2013).

Tendo em vista que Poaceae é a segunda maior família em número de espécies na PIAP (Souza et al. 2009) e que o conhecimento sobre a composição da flora agrostológica desta área é ainda deficiente, objetivou-se, neste trabalho, analisar a composição da flora graminosa na área, ampliando, desta forma, o conhecimento acerca da família nesta região e ressaltando a relevância regional da Área de Proteção Ambiental Federal das Ilhas e Várzeas do Rio Paraná (APA-IVRP) e do Parque Estadual das Várzeas do Rio Ivinhema (PEVRI).

\section{Material e métodos}

APlanície de Inundação do Alto Rio Paraná (PIAP) é sazonalmente submetida a drásticas modificações em suas características bióticas e abióticas, decorrentes do regime de cheias (UEM 2015). Esta planície está inserida na APA-IVRP (Área de Proteção Ambiental das Ilhas e Várzeas do Rio Paraná), cuja extensão é de $5.268 \mathrm{~km}^{2}$, e faz parte da Reserva da Biosfera da Mata Atlântica - MAB/UNESCO, compondo o último trecho livre de barragens do Rio Paraná em território brasileiro (Agostinho et al. 2004). Recentemente, a PIAP foi reduzida pela construção da barragem da Usina Hidrelétrica Engenheiro Sérgio Motta (Porto Primavera), entre os Estados de São Paulo e Mato Grosso do Sul (Stevaux et al. 2009).

A área na qual foi conduzido este estudo (i.e., Alto Rio Paraná - trecho entre a confluência dos rios Paranaíba e Grande, até os antigos Saltos de Sete Quedas, em Guaíra, PR) está inserida na metade superior da APA-IVRP e compreende cerca de 1.100 $\mathrm{km}^{2}$ (UEM 2015), constituindo o Sítio 6 do Programa Nacional de Pesquisas Ecológicas de Longa Duração (PELD, Sítio 6). Localmente, abrange as zonas ripárias da APA-IVRP e localiza-se no Rio Paraná e em alguns tributários, entre as coordenadas $22^{\circ} 38^{\prime}-22^{\circ} 57^{\prime} \mathrm{S}$ e $53^{\circ} 05^{\prime}-53^{\circ} 36^{\prime} \mathrm{O}$. A sua porção oriental (margem esquerda), inclui parte dos municípios paranaenses de Marilena, São Pedro do Paraná, Porto Rico e Querência do Norte. Na porção ocidental (margem direita), inclui parte dos municípios sul-matogrossenses de Batayporã, Ivinhema, Jateí e Taquarussu. A maior parte das áreas amostradas ao longo dos rios Guiraí, Curupaí e Ivinhema faz parte do PEVRI (Parque Estadual das Várzeas do Rio Ivinhema) (figura 1).

Santos et al. (1992) caracterizaram a margem esquerda do Rio Paraná com litologias específicas, com arenitos cretáceos, consolidados da Formação Caiuá, de estratificação cruzada, que formam barrancos altos e estáveis de 10-20 m de altura, ocorrendo ainda pequenas áreas de várzea com cotas de 280-400 m. Sobre os arenitos ocorrem sedimentos de terraços e da planície fluvial (Souza-Filho 1994).

O clima da região é o tropical sub-quente. A temperatura média anual é de $20^{\circ} \mathrm{C}$, com um ou dois meses secos e precipitações maiores que $1.500 \mathrm{~mm} /$ ano (IBGE 2012).

A PIAP está inserida no bioma Mata Atlântica, entre o Cerrado, no Mato Grosso do Sul, e a Floresta Estacional Semidecidual, no Paraná, sendo a várzea e a floresta ripária elementos típicos da área estudada (Souza et al. 1997, IBGE 2012). Fragmentos florestais mais preservados ocorrem nestas áreas ripárias, entremeados à vegetação em processo de sucessão natural, proporcionada pela criação da APA-IVRP, tais como a Mata do Araldo, na margem esquerda do Rio Paraná, em Porto Rico, e a Mata do Finado Raimundo, na margem esquerda do Rio Ivinhema. A vegetação das ilhas do Rio Paraná pode ser enquadrada nas formações pioneiras de influência fluvial, com suas diversas associações (Campos \& Souza 1997). Nos locais de topografia rebaixada e sazonalmente alagáveis, ocorrem campos naturais, principalmente nas áreas do PEVRI.

A flora fanerogâmica da PIAP é composta por cerca de 1.000 espécies (Souza et al. 2009), das quais $72 \%$ representam arbustos, subarbustos, ervas e trepadeiras, e apenas $28 \%$ pertencem ao estrato arbóreo.

Para a amostragem, foram realizadas coletas abrangendo os diversos ambientes (e.g., canais, córregos, lagoas, rios, riachos, ilhas, dentre outros), em períodos de cheia e de vazante. As coletas foram iniciadas em dezembro de 2009 e encerradas em 2013. Cada expedição teve duração de quatro a cinco dias, perfazendo um total de 59 dias de amostragens. Foram realizadas coletas tanto a pé quanto em barcos. 
Coletas em terra firme foram realizadas segundo o método proposto por Filgueiras et al. (1994). Complementarmente, foram efetuadas coletas pontuais em locais onde era possível o acesso a pé. Algumas áreas extremamente alagadiças ao longo dos rios Curupaí, Guiraí, Samambaia, Vitória e várzeas, não foram amostradas por serem, na ocasião, inacessíveis com os equipamentos disponíveis à equipe.

O processamento do material botânico foi realizado de acordo com os procedimentos usuais em taxonomia de fanerógamas (Fidalgo \& Bononi 1989, Bridson \& Forman 1998), exceto para os bambus, cujo processamento seguiu Soderstrom \& Young (1983) e IBGE (2012).

Além das amostras obtidas durante os trabalhos de campo, foram analisados os materiais coletados em levantamentos florísticos anteriormente realizados no Alto Rio Paraná, bem como o material obtido pela equipe do Laboratório de Mata Ciliar/Nupélia/ UEM em expedições organizadas entre 1986 e 2015. Todas as amostras obtidas foram georreferenciadas utilizando-se aparelho GPS Garmin ${ }^{\circledR}$. Coordenadas

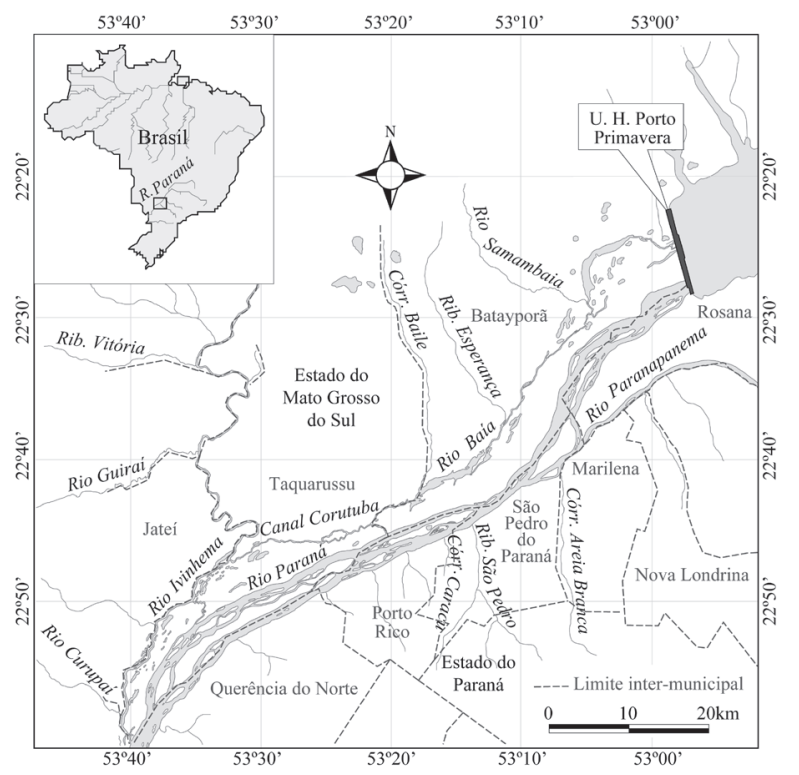

Figura 1. Localização da área estudada. Planície de Inundação do Alto Rio Paraná e seu entorno, Mato Grosso do Sul e Paraná, Brasil. (Fonte: IBGE. Diretoria de Geodésia de Cartografia. Carta do Brasil - Loanda (PR). Folha SF.22-Y-A MIR 484. [Rio de Janeiro], 1984. Escala: 1: 250.000. Adaptado por Jaime Luis Lopes/Nupélia/UEM (2014).

Figure 1. Study site. Upper Paraná River Floodplain and its environs, Mato Grosso do Sul and Paraná, Brazil. (Source: IBGE. Diretoria de Geodésia de Cartografia. Carta do Brasil - Loanda (PR). Folha SF.22-Y-A MIR 484. [Rio de Janeiro], 1984. Scale: 1: 250.000. Adapted by Jaime Luis Lopes/Nupélia/UEM (2014). complementares foram obtidas a partir do software Google Earth ${ }^{\circledR}$. Estes dados foram incorporados às etiquetas das exsicatas depositadas em coleções de herbário, prioritariamente no acervo do herbário da Universidade Estadual de Maringá (HUEM) [acrônimos de acordo com Thiers (2015)]. Duplicatas serão doadas a diversos herbários, preferencialmente aos herbários dos estados de origem do material (DDMS, CGMS, FUEL e MBM), além do herbário do Instituto de Botânica, SP.

Adicionalmente, foi realizada consulta a coleções informatizadas disponibilizadas na rede SpeciesLink (http://inct.splink.org.br), com especial atenção aos herbários dos Estados de Mato Grosso do Sul (CGMS) e Paraná (FUEL, HCF, HUEM e MBM), além de posterior consulta ao herbário DDMS, aos quais, quando necessário, foram solicitados empréstimos. Além disso, foram também visitados os herbários BAA, CGMS, FUEL, IAC e SP.

Para a identificação das amostras, foi utilizada bibliografia especializada, além de eventual consulta a outros especialistas. A terminologia morfológica adotada segue, em linhas gerais, Longhi-Wagner et al. (2001) e a classificação segue Soreng et al. (2015). A classificação das espécies em nativas ou naturalizadas/ exóticas segue Filgueiras et al. (2015).

\section{Resultados e Discussão}

A partir da análise de 916 espécimes, coletados entre 1988 e 2015 nos diferentes ambientes da PIAP e seu entorno, Mato Grosso do Sul/Paraná, foram identificadas 94 espécies de Poaceae, taxonomicamente posicionadas em 50 gêneros, 14 tribos e seis subfamílias (tabela 1).

Panicoideae (64 spp.) é a subfamília mais representativa na área estudada, abrangendo $68,08 \%$ do total das espécies. As demais espécies distribuem-se entre as subfamílias Chloridoideae (12 spp.), Bambusoideae (11 spp.), Oryzoideae (quatro spp.), Arundinoideae (duas spp.) e Pooideae (uma sp.).

Dentre os gêneros encontrados, aqueles com maior número de espécies foram Paspalum (11 spp.), Panicum e Eragrostis (seis spp. cada), Urochloa (cinco spp.), seguidos por Axonopus, Cenchrus, Digitaria, Guadua, Hymenachne e Rugoloa (três spp. cada). Os demais gêneros estão representados por duas ou uma espécie apenas.

Quatorze espécies foram coletadas na PIAP pela primeira vez: Arundo donax, Bambusa tuldoides, Bambusa vulgaris, Chloris elata, Dendrocalamus 


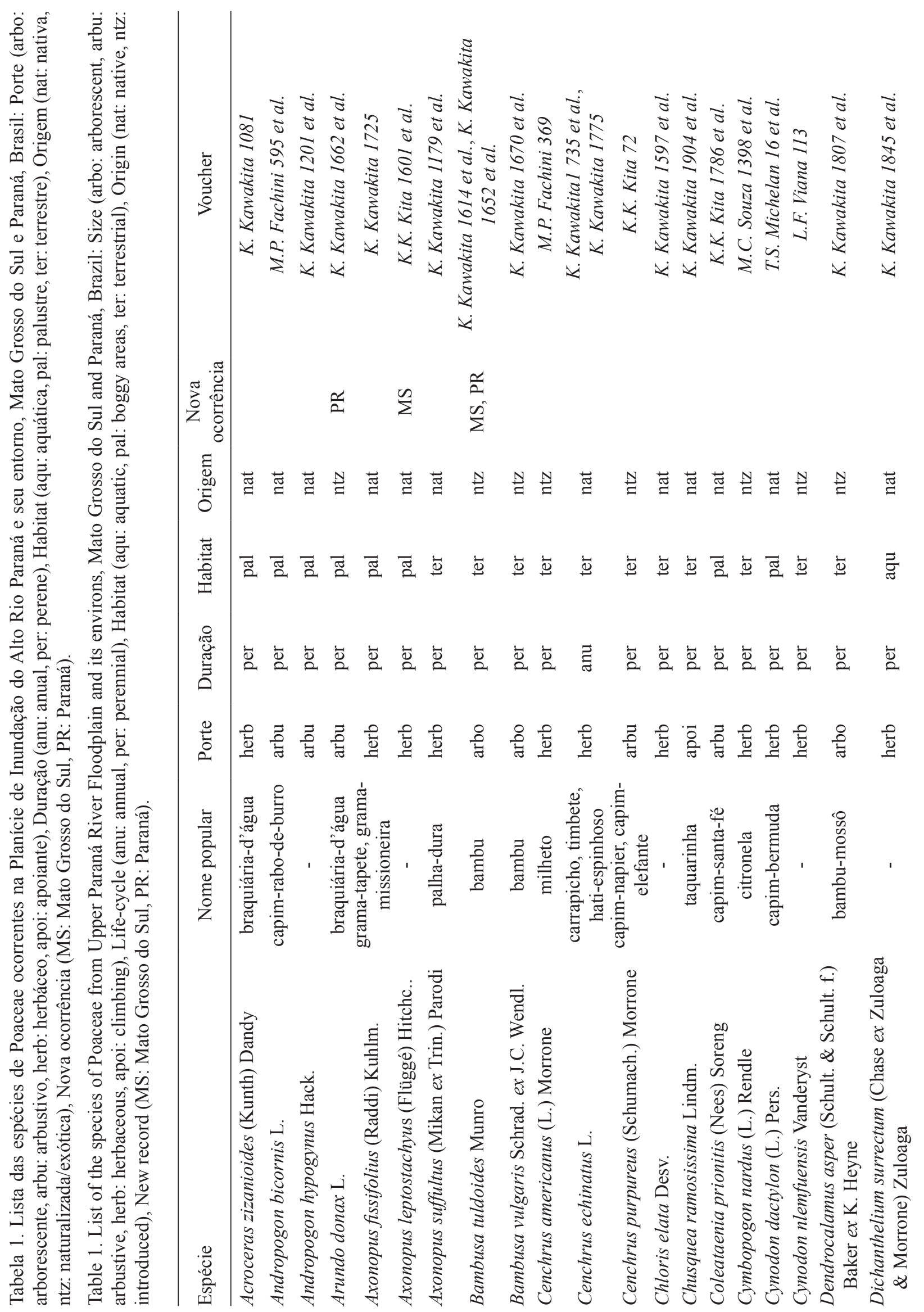




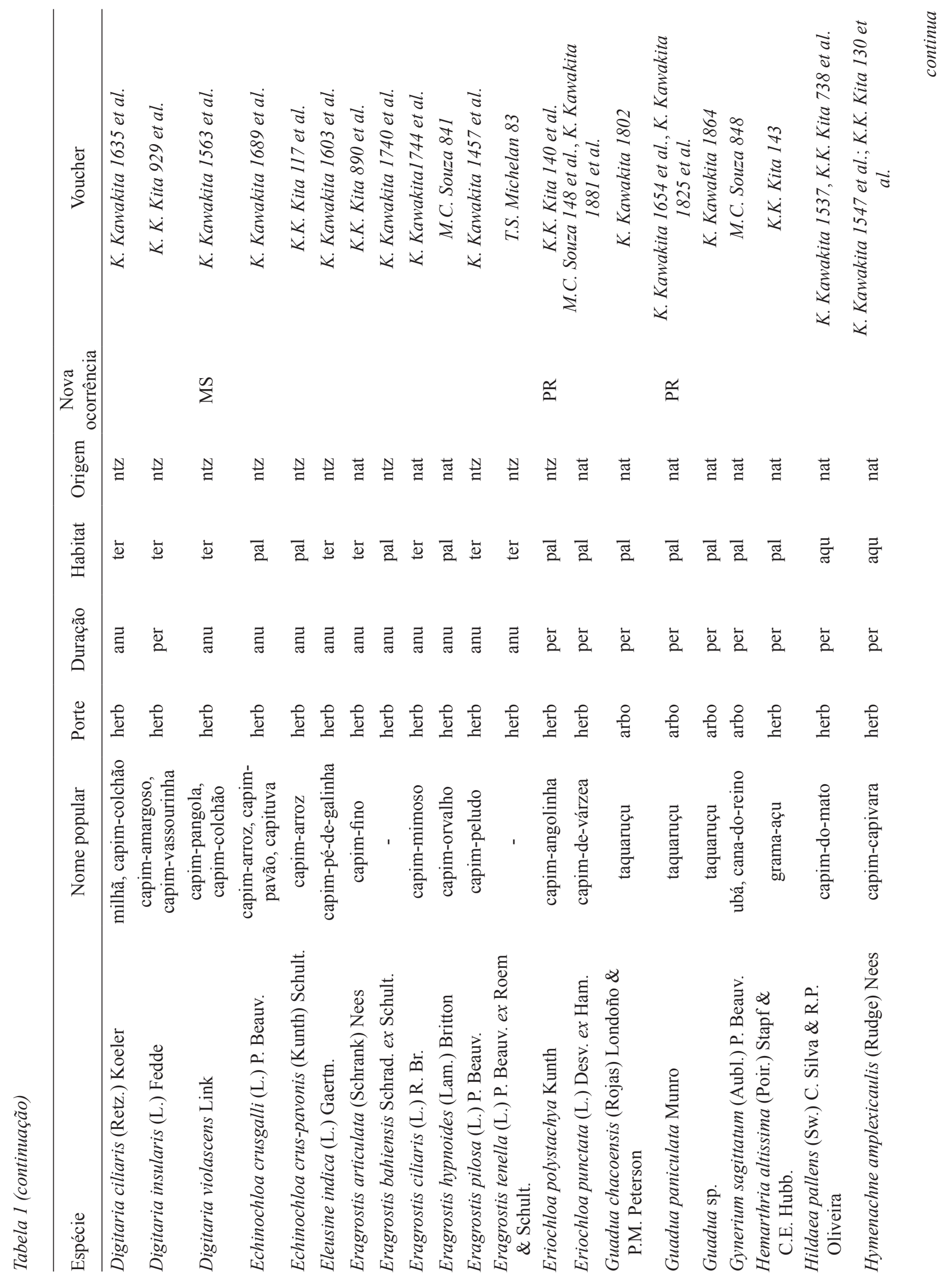




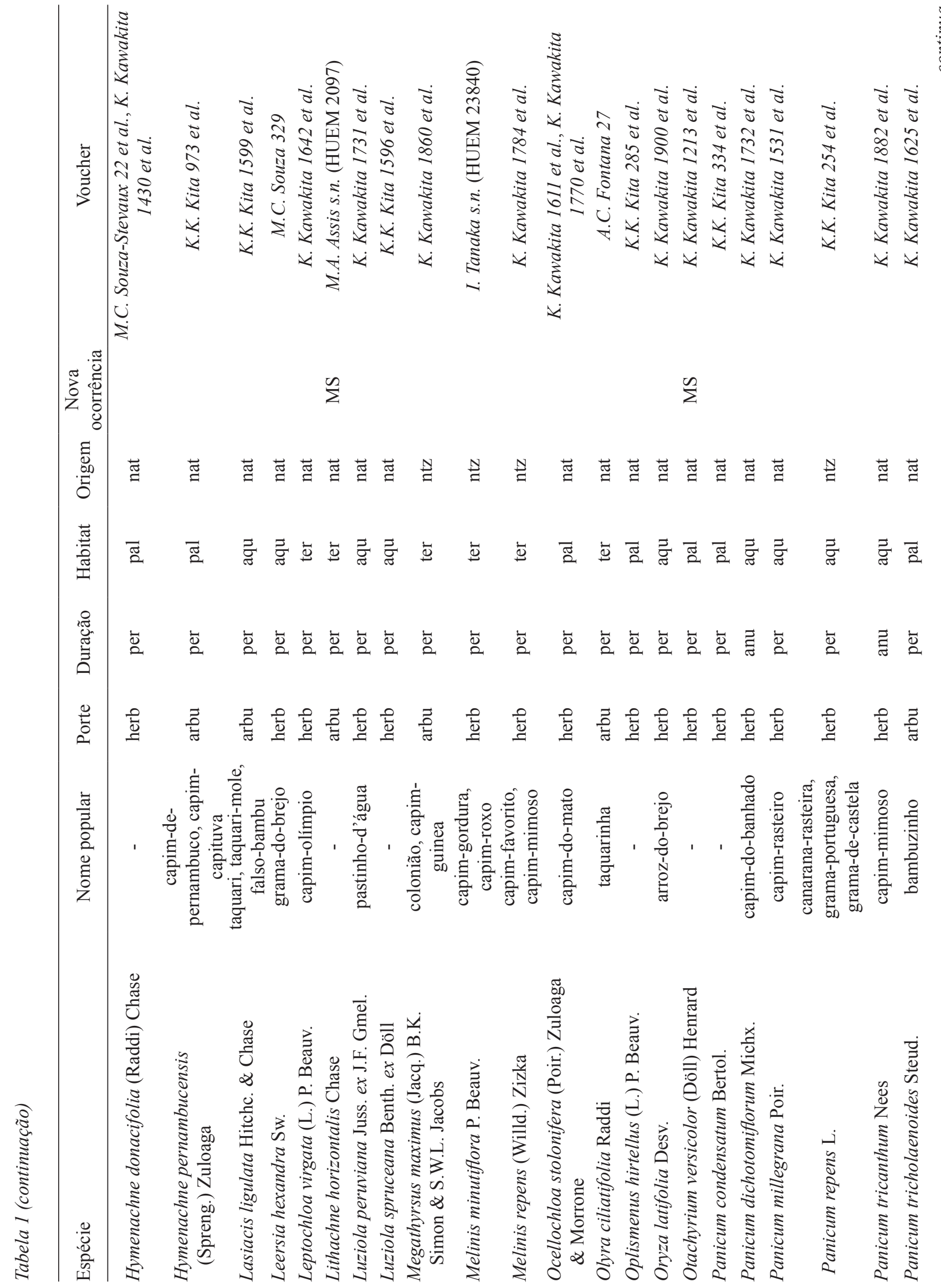




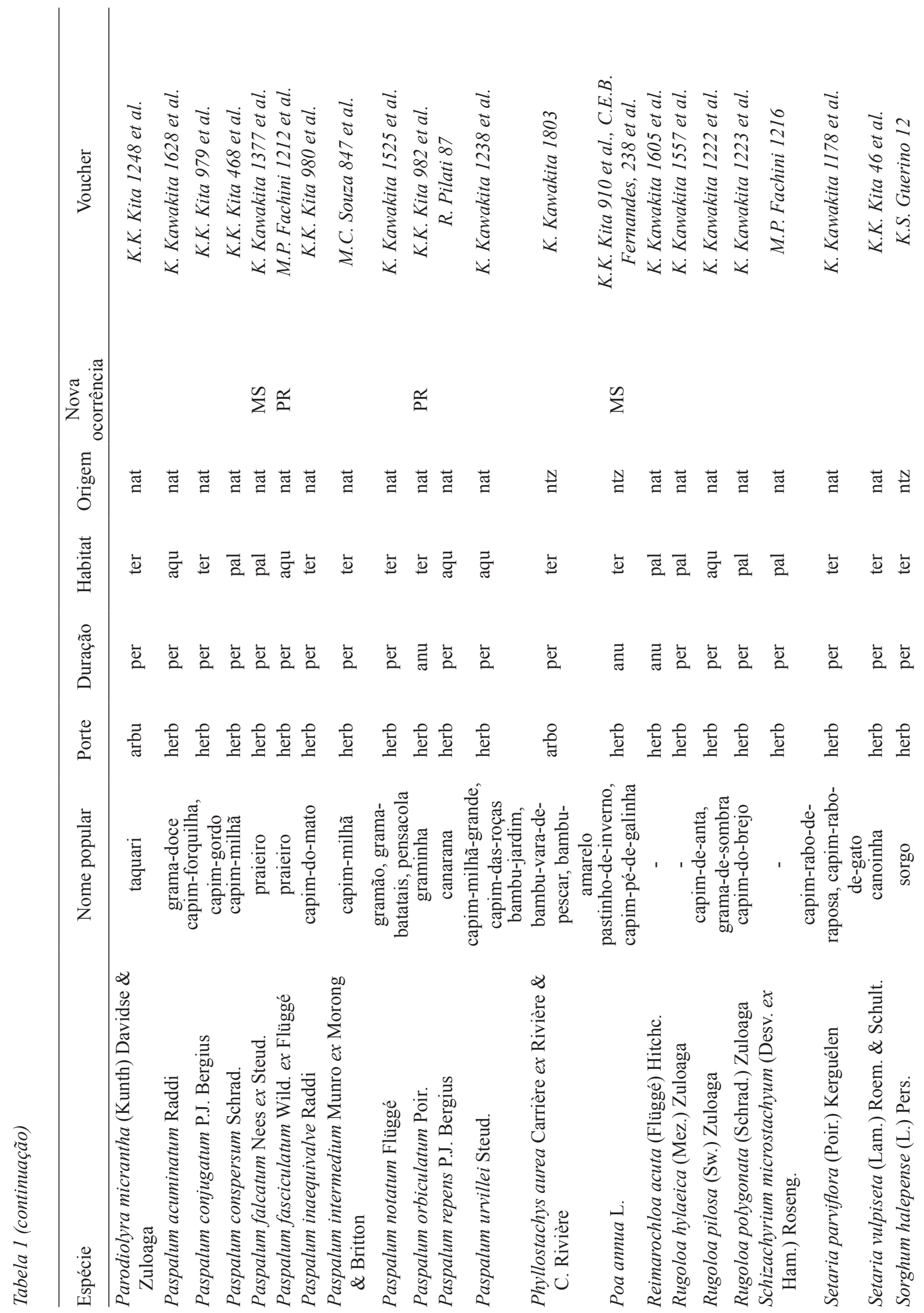




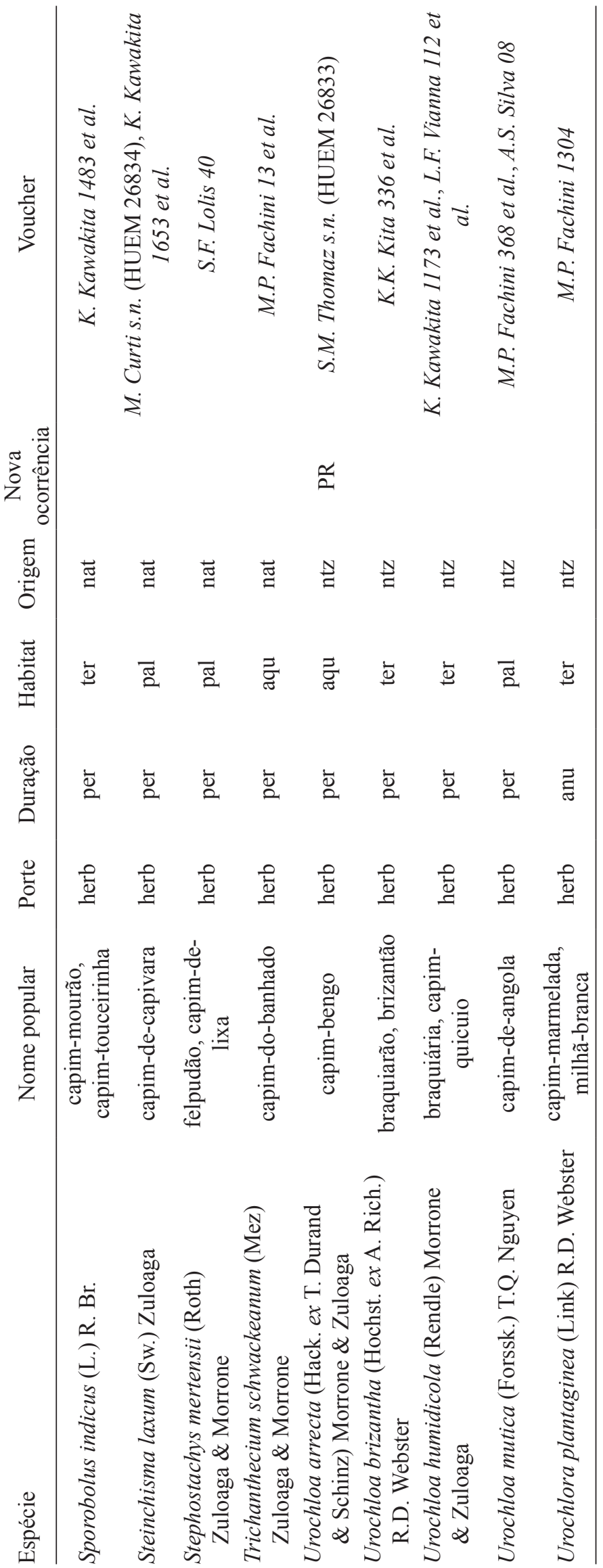


asper, Dichanthelium surrectum, Eragrostis pilosa, Leptochloa virgata, Luziola peruviana, Oryza latifolia, Panicum millegrana, Paspalum acuminatum e Phyllostachys aurea, além de um espécime de Guadua (Guadua sp.), que, certamente, não corresponde a nenhuma das espécies do gênero já registradas na região.

O número total de espécies de Poaceae (94 spp.) pode ser considerado elevado para a região em comparação com outras famílias fanerogâmicas, provavelmente em decorrência da diversidade de ambientes dessa planície, com áreas de topografia variada, formando baixios, diques marginais, inúmeras lagoas e ilhas, além da ocorrência de inundação e impactos antrópicos de diferentes graus e formas. De acordo com Boldrini et al. (2005), o sucesso das gramíneas está baseado na variabilidade e versatilidade de suas formas biológicas, adaptadas às diferentes pressões impostas pelo ambiente.

Novas ocorrências foram registradas para os Estados do Mato Grosso do Sul (sete spp.) e do Paraná (sete spp.), com três espécies comums a estes dois estados (tabela 1). Este elevado número de novos registros ressalta a importância da continuidade de estudos florísticos locais e constitui forte argumento para a promoção de políticas e ações que objetivem a efetiva conservação da PIAP e do seu entorno, tanto no PEVRI quanto na APA-IVRP.

A maior parte das gramíneas do Alto Rio Paraná apresenta o porte herbáceo $(77,66 \%)$, seguido do arbustivo $(12,77 \%)$, arborescente $(8,51 \%)$ e apoiante $(1,06 \%)$. Estes resultados estão em conformidade com os obtidos por Junk \& Piedade (1994), pois, em áreas alagáveis, é esperado que a maioria das espécies apresente o porte herbáceo em decorrência das constantes modificações que ocorrem no ambiente, ocasionadas pelos períodos de águas altas e de águas baixas. Nos ciclos plurianuais hipohídricos ocorre expansão das plantas de porte herbáceo (Kita \& Souza 2003).

Considerando-se todas as espécies de Poaceae da PIAP, $80,85 \%$ são perenes e $19,15 \%$ anuais. Rodrigues-da-Silva \& Filgueiras (2003) obtiveram resultados semelhantes $(80,4 \%$ de perenes $)$, em estudo no Distrito Federal. Dentre as espécies de porte herbáceo, a maioria $(75,34 \%)$ é perene e as demais $(24,66 \%)$ anuais. Este sucesso das gramíneas de porte herbáceo e perenes em planícies de inundação pode estar relacionado com as condições de anoxia do sedimento (Worbes 1997). Outros fatores como diferentes posições topográficas e propriedades físico-químicas do sedimento também podem estar relacionados (Pagotto et al. 2011). As semelhanças nas condições edáficas e aspectos geomorfológicos entre a PIAP e o Pantanal podem ser também apontados como prováveis fatores para a existência de um considerável número de espécies (63 spp.) comuns a estas duas planícies inundáveis (Pott et al. 1986, Allem \& Valls 1987, Pott et al. 1989, Pott et al. 1992, Pott 1994, Prado et al. 1994, Silva et al. 1997, Heckman 1998, Pott et al. 1999, Pott 2000, Pott \& Pott 2000, Rebellato $\&$ Nunes-da-Cunha 2005, Pott \& Pott 2009, Nunesda-Cunha \& Junk 2011, Pott et al. 2011, Filgueiras et al. 2015).

Na PIAP, 42,55\% das espécies de gramíneas classificam-se como terrestres, seguidas pelas espécies palustres $(37,24 \%)$ e aquáticas $(20,21 \%)$ (tabela 1$)$. Apesar de a maior parte da área estudada fazer parte da planície de inundação, existem diversos subambientes que favorecem a instalação e sobrevivência das espécies terrestres. A retenção da água pelos muitos represamentos a montante provavelmente colabora para o estabelecimento e sucesso das espécies terrestres. Estudos realizados por Slusarski \& Souza (2012), nos quais foram observadas alterações estruturais e florísticas, com diminuição na densidade de espécies típicas de áreas úmidas e aumento da densidade de espécies de ambientes secos em fragmento florestal em Porto Rico, PR, corroboram a hipótese de que as alterações provocadas pelo controle do nível da água estejam afetando a composição da vegetação marginal do Rio Paraná.

Avaliando-se a origem de cada espécie (nativa ou naturalizada/exótica), observou-se que $68,08 \%$ das espécies da PIAP são nativas. Este fato ressalta a importância da área para a conservação da biodiversidade, apesar dos intensos processos de antropização, que se refletem, além de outros aspectos, na ocorrência de espécies naturalizadas e/ou invasoras $(31,92 \%)$, indicadoras biológicas do grau de perturbação ambiental ao qual determinada área está submetida (Filgueiras 1990, Agostinho 1997, UEM, 2015).

Dentre as espécies naturalizadas/exóticas, despontam como invasoras o capim-colonião (Megathyrsus maximus), o capim-bengo (Urochloa arrecta) e o capim-gordura (Melinis minutiflora). A primeira foi utilizada na composição de pastagens que se estendiam até as margens dos rios da região; atualmente, ela domina o ambiente ripário em diversos trechos, competindo com a flora nativa, especialmente as herbáceas. Segundo COMAFEN (2014), o 
controle de Megathyrsus maximus, em projetos de reflorestamento, tem sido problemático, o que foi confirmado no presente estudo. Urochloa arrecta tem causado impactos negativos em reservatórios de usinas hidrelétricas neotropicais (Mormul et al. 2010, Carniatto et al. 2013) e tem sido documentada em corpos d'água da PIAP (Michelan et al. 2013). Melinis minutiflora, apesar de ainda ser pouco representativa na área, apresenta alto potencial invasor, especialmente em Unidades de Conservação (Martins et al. 2007). Sugere-se aqui o monitoramento das populações dessas três espécies na área como uma das ações de manejo da APA-IVRP.

Dentre os bambus de grande porte exóticos, destacam-se Bambusa tuldoides, Bambusa vulgaris, Dendrocalamus asper e Phyllostachys aurea, encontrados nos ambientes ripários antropizados. Estes bambus são cultivados e utilizados localmente como plantas ornamentais, alimentícias (broto de bambu) e artesanais (colmos). As três primeiras não apresentam potencial invasor conhecido. Phyllostachys aurea, entretanto, apesar de apresentar distribuição localmente restrita, é uma espécie exótica com grande potencial invasor (Shirasuna et al. 2013).

Os bambus herbáceos encontrados na PIAP (Lithachne horizontalis, Olyra ciliatifolia e Parodiolyra micrantha) são todos nativos. Dentre os bambus arborescentes nativos, apenas Chusquea ramosissima apresenta hábito apoiante, sendo comum ao longo da bacia do Rio Paraná (Smith et al. 1981).

Foram amostradas 25 espécies nativas ocupando áreas em estádios iniciais de sucessão, em barras arenosas, lagoas temporárias e/ou locais alterados da PIAP. São elas: Andropogon bicornis, Axonopus fissifolius, Axonopus leptostachyus, Cenchrus echinatus, Chloris elata, Coleataenia prionitis, Cynodon dactylon, Eragrostis articulata, Eragrostis ciliaris, Eragrostis hypnoides, Eriochloa punctata, Hemarthria altissima, Luziola spruceana, Panicum condensatum, Panicum dichotomiflorum, Paspalum conjugatum, Paspalum conspersum, Paspalum inaequivalve, Paspalum notatum, Paspalum orbiculatum, Paspalum repens, Rugoloa hylaeica, Setaria parviflora, Sporobolus indicus e Steichisma laxum.

Duas dentre as cerca de 500 espécies de Poaceae endêmicas do Brasil (Filgueiras et al. 2015) ocorrem na PIAP. São elas: Acroceras zizanioides (Mato Grosso do Sul e Paraná) e Lithachne horizontalis (Mato Grosso do Sul). A primeira tem sido coletada regularmente nos remanescentes florestais da região desde 1992; a segunda, entretanto, foi coletada na região pela última vez em 1991, não tendo sido reencontrada durante o presente estudo - fato que sugere sua raridade local. Tendo em vista que Lithachne horizontalis é uma espécie em perigo de extinção, novas expedições deverão ser conduzidas com o objetivo de localizar novos indivíduos, realizar novas coletas ou, eventualmente, comprovar sua extinção local.

$\mathrm{Na}$ margem esquerda do Córrego Caracu, afluente do Rio Paraná, próximo a um bebedouro de bovinos, pastagem e cultura agrícola, foi coletada também Paspalum acuminatum, outra espécie nativa e localmente rara. Sua ocorrência em local altamente vulnerável indica que a espécie corre perigo de extinção local.

Foram encontrados registros de uso ou potencial forrageiro para 51 das 64 espécies de gramíneas nativas da PIAP, que sozinhas representam 54,25\% do número total de espécies da área estudada (Pott 1985, Filgueiras 1992, Kissmann 1997, Lorenzi 2000, Nascimento \& Renvoize 2001, Souza \& Lorenzi 2008). Filgueiras (1992) obteve um valor aproximado (44\% do total de espécies) para o Distrito Federal. Filgueiras (2012) discute a necessidade da ampliação de pesquisas sobre o uso de espécies de gramíneas nativas em pastagens e na recuperação de áreas degradadas, além da carência de investimentos para pesquisa nesta área. A indicação de espécies com potencial forrageiro é de especial interesse para o estudo e manejo da fauna herbívora nativa e também para o estudo de plantas forrageiras com potencial para domesticação (T.S. Filgueiras \& R.S. Rodrigues, dados não publicados). Segundo Allem \& Valls (1987), as gramíneas Hymenachne amplexicaulis, Steinchisma laxum, Paspalum conjugatum e Paspalum repens fazem parte da dieta da capivara [Hydrochoerus hydrochaeris (Linnaeus, 1766)] e do veado [Ozotoceros bezoarticus (Linnaeus, 1758)], que se alimentam basicamente de gramíneas nativas. Lagomorfos e roedores nativos utilizam-se também de gramíneas em sua alimentação. Pássaros granívoros alimentam-se frequentemente das cariopses de gramíneas nativas. Durante os trabalhos de campo, o periquito-rei [Eupsittula aurea (Gmelin, 1944)] foi observado alimentando-se das espiguetas inteiras de Guadua paniculata (J.C. Barbosa, dados não publicados).

Em setembro de 2000 , foi coletado material fértil de uma touceira isolada de taboca (Guadua paniculata) (K.K. Kita 1598, HUEM), às margens do canal do Rio Baía, município de Batayporã, MS. 
Uma segunda floração desta mesma espécie, desta vez de forma gregária, foi observada de setembro de 2011 (J.C. Barbosa, HUEM 27437) a março de 2013 (K. Kawakita 1654 et al., HUEM). Desta segunda vez, verificou-se que, depois da floração, quase todos os colmos secaram e morreram. No terceiro ano após o início da floração, foram verificados indivíduos jovens, com cerca de um metro de altura, crescendo juntamente com outras espécies da flora local, embaixo das touceiras senescentes e mortas. No quarto ano, alguns indivíduos jovens alcançavam até dois metros de altura. Esta espécie de taboca é o bambu nativo mais comum na PIAP, principalmente ao longo dos diques marginais do Rio Paraná, ilhas, Canal do Rio Baía e Canal Corutuba. Habita, preferencialmente, margens de cursos d'água, ao longo da mata ciliar (Filgueiras 1988), formando densas populações de difícil acesso. Por se tratar de uma espécie que ocupa áreas relativamente extensas, é, às vezes, percebida como invasora, porém, trata-se de um componente importante da flora graminosa nativa dos ambientes ripários.

Em setembro de 2013 foi observado o florescimento de mais uma espécie de bambu, taquarinha (Chusquea ramosissima) (K. Kawakita 1904 et al., HUEM). Alguns colmos floresceram em um remanescente florestal estreito, de cerca de $5 \mathrm{~m}$ de largura, na margem direita do Córrego Caracu, Porto Rico, $\mathrm{PR}$, próximo à nascente. Os colmos floríferos morreram após o florescimento. Colmos vegetativos vivos nestas touceiras foram observados em abril de 2014. Não foram observadas plântulas sob as touceiras das plantas mães e nem nas imediações. Esta espécie ocupa o sub-bosque de mata ciliar e, segundo Smith et al. (1981), é típica da bacia do Rio Paraná. Seu ciclo de florescimento é, provavelmente, de 20-25 anos (Clark 2001).

\section{Considerações finais}

A flora agrostológica da PIAP, em 1997, ano da criação da APA-IVRP, totalizava 17 espécies (Souza et al. 1997). Entre 1998 e 2015, este número sofreu incremento de 77 espécies, perfazendo um total de 94 táxons registrados. A criação da APA, a diminuição dos pulsos de inundação pelas hidrelétricas a montante e o desenvolvimento de um projeto de pesquisa com ênfase nas Poaceae foram, provavelmente, fatores determinantes para este incremento. Apesar de a ocupação humana e suas atividades em parte da PIAP e da regulação na vazão deste trecho de rio, essa área abriga uma considerável diversidade de espécies, não somente de Poaceae, mas de outras famílias botânicas e animais.

O estado de conservação da área é, no entanto, espacialmente heterogêneo (UEM, 2015). Foi verificado que, nas proximidades da cidade de Porto Rico e do distrito de Porto São José, Município de São Pedro do Paraná, e nas áreas de topografia mais elevada, a pressão antrópica é maior, enquanto que nas áreas mais distantes e nos baixios alagados ela é menor, especialmente na área de abrangência do PEVRI. A presença de bovinos, porcos e outros animais domésticos, certamente contribuiu para a degradação de trechos das zonas ripárias da região. Nas áreas mais elevadas, foi observada a presença de bovinos, mesmo dentro da APA, o que pode contribuir para a degradação da fitobiversidade e comprometer o processo de recuperação iniciado a partir de 1998, após a criação da APA-IVRP e do PEVRI ( $c f$., Campos \& Dickinson 2005).

Durante os trabalhos de campo, constatou-se que algumas espécies de gramíneas distribuem-se num padrão de manchas, daí a necessidade de análises quantitativas em áreas representativas desta planície a fim de se verificar quais são as espécies mais frequentes e abundantes nos diferentes hábitats da região. Sugere-se, ainda, um monitoramento da flora graminosa desta planície como suporte para a conservação, priorizando as áreas pouco coletadas e especialmente a metade inferior da APA-IVRP, incluindo o Parque Nacional de Ilha Grande, com o intuito de se realizarem, futuramente, eventuais estudos comparativos com a área aqui estudada.

\section{Agradecimentos}

À Doutora Maria Conceição de Souza (PGB/ PEA/DBi/UEM) pelo apoio logístico e administrativo; aos Doutores Arnildo Pott, Vali Joana Pott (Panicum trichanthum), Ana Zanin (Andropogoneae) e José Francisco Montenegro Valls pelo auxílio com algumas identificações/confirmações; aos Doutores Pedro Lage Viana, Mauro Parolin, Evanilde Benedito, Simone Slusarski, André Padial, Eduardo Pereira Cabral Gomes, Maria Auxiliadora Milaneze-Gutierre, Maria Margarida da Rocha Fiuza de Melo, Maria Salete Ribelato Arita, Erivelto Goulart e Paulo Cesar Rocha, pelas valiosas sugestões; à equipe do Laboratório de Vegetação Ripária/Nupélia/UEM e aos funcionários do Nupélia/UEM pelo auxilio nas coletas de campo e atividades laboratoriais, em especial, ao Carlos E.B. Fernandes; ao Nupélia/UEM, CNPq/PELD-site 6, 
pelo apoio logístico e parte do auxílio financeiro; ao Programa de Pós-graduação em Biologia Comparada da Universidade Estadual de Maringá (PGB/UEM). RSR agradece ao CNPq e a CAPES pelos auxílios recebidos.

\section{Literatura citada}

Agostinho, A.A. 1997. Qualidade dos habitats e perspectivas para a conservação. In: A.E.A. Vazzoler, A.A. Agostinho \& N.S. Hahn (eds.). A planície de inundação do alto rio Paraná: aspectos físicos, biológicos e socioeconômicos. Universidade Estadual de Maringá, Maringá. pp. 455-460.

Agostinho, A.A., Rodrigues, L., Gomes, L.C., Thomaz, S.M. \& Miranda, L.E. 2004. Structure and functioning of the Paraná River and its floodplain. LTER - site 6 (PELD Sítio 6). Universidade Estadual de Maringá, Maringá.

Alcântara, P.B. \& Bufarah, G. 1982. Plantas forrageiras: gramíneas \& leguminosas. 1 ed., Nobel, São Paulo.

Allem, A.C. \& Valls, J.F.M. 1987. Recursos forrageiros nativos do pantanal mato-grossense. EMBRAPA, Brasília.

Boldrini, I.I., Longhi-Wagner, H.M. \& Boechat, S.C. 2005. Morfologia e taxonomia de gramíneas Sul-RioGrandenses. Editora da Universidade Federal do Rio Grande do Sul, Porto Alegre.

Bridson, D. \& Forman, L. 1998. The herbarium handbook. 3 ed., Royal Botanic Gardens, Kew.

Campos, J.B. 2004. Spatial characterization of the vegetation. In: S.M. Thomaz, A.A. Agostinho \& N.S. Hahn (eds.). The upper Paraná river and its floodplain: physical aspects, ecology and conservation. Backhuys Publishers, Leiden, pp. 369-380.

Campos, J.B. \& Dickinson, G. 2005. Regeneração de florestas na Área de Proteção Ambiental - APA das Ilhas e Várzeas do Rio Paraná. Cadernos da biodiversidade 5: 50-59.

Campos, J.B. \& Souza, M.C. 1997. Vegetação. In: A.E.A. Vazzoler, A.A. Agostinho \& N.S. Hahn (eds.). A planície de inundação do alto rio Paraná: aspectos físicos, biológicos e socioeconômicos. Universidade Estadual de Maringá, Maringá, pp. 333-344.

Carniatto, N., Thomaz, S.M., Cunha, E.R., Fugi, R. \& Ota, R.R. 2013. Effects of an invasive alien Poaceae on aquatic macrophytes and fish communities in a Neotropical reservoir. Biotropica 45: 747-754.

Chase, M.A. 1991. Primeiro livro de gramíneas: noções sobre a estrutura com exemplos da flora brasileira. 1 ed., Instituto de Botânica, São Paulo.

Clark, L.G. 2001. Chusquea. In: H.M. Longhi-Wagner, V. Bittrich, M.G.L. Wanderley \& G.J. Shepherd (eds.). Flora Fanerogâmica do Estado de São Paulo. Fapesp \& HUCITEC, São Paulo, v. 1, pp. 24-36.
COMAFEN (Consórcio Intermunicipal da APA Federal do Noroeste do Paraná). 2014. Disponível em http:// www.comafen.org.br/projetos.php?id=3 (acesso em 10-VII-2014).

Corradini, F.A. 2006. Processos de conectividade e a vegetação ripária do alto rio Paraná - MS. Dissertação de Mestrado, Universidade Estadual de Maringá, Maringá.

Fidalgo, O. \& Bononi, V.L.R. (coords.). 1989. Técnicas de coleta, preservação e herborização de material botânico. Secretaria do Meio Ambiente, Instituto de Botânica, São Paulo.

Filgueiras, T.S. 1988. Bambus nativos do Distrito Federal, Brasil (Gramineae: Bambusoideae). Revista Brasileira de Botânica 11: 47-66.

Filgueiras, T.S. 1990. Gramíneas africanas: introdução no Brasil. Cadernos de Geociências 5: 57-63.

Filgueiras, T.S. 1992. Gramíneas forrageiras nativas no Distrito Federal, Brasil. Pesquisa Agropecuária Brasileira 27: 1103-1111.

Filgueiras, T.S. 2012. Gramíneas (Poaceae) no CentroOeste do Brasil. Heringeriana 6: 47-48.

Filgueiras, T.S., Brochado, A.L., Nogueira, P.E. \& Guala, G.F. 1994. Caminhamento: um método expedito para levantamentos florísticos qualitativos. Cadernos de Geociências 12: 39-43.

Filgueiras, T.S., Canto-Dorow, T.S., Carvalho, M.L.S., Dórea, M.C., Ferreira, F.M., Mota, A.C., Oliveira, R.C., Oliveira, R.P., Reis, P.A., Rodrigues, R.S., Santos-Gonçalves, A.P., Shirasuna, R.T., Silva, A.S., Silva, C., Valls, J.F.M., Viana, P.L., Welker, C.A.D., Zanin, A. \& Longhi-Wagner, H.M. 2015. Poaceae. In: Lista de Espécies da Flora do Brasil. Jardim Botânico do Rio de Janeiro. Disponível em http://floradobrasil. jbrj.gov.br/jabot/floradobrasil/FB193 (acesso em 6-VIII-2015).

Hayakawa, E.H., Couto, E.V., Souza-Filho, E.E., Prado, B.R. \& Paula, P.F. 2010. Análise temporal da planície de inundação do alto rio Paraná (região de Porto Rico PR) através de dados de sensoreamento remoto. Boletim de Geografia 28: 115-126.

Heckman, C.W. 1998. The Pantanal of Poconé: biota and ecology in the northern section of the world's largest pristine wetland (Monographiae Biologicae). Kluwer Academic Publishers, Dordrecht, Netherlands.

IBGE - Instituto Brasileiro de Geografia e Estatística. 2012. Manual técnico da vegetação brasileira. 2 ed., Manuais técnicos em Geociências, Rio de Janeiro. pp. 1-139.

Judd, W.S., Campbell, C.S., Kellogg, E.A., Stevens, P.F. \& Donoghue, M.J. 2009. Sistemática vegetal: um enfoque filogenético. 3 ed., Artmed, Porto Alegre.

Junk, W.J. \& Piedade, M.T. 1994. Species diversity and distribution of herbaceous plants in the floodplain of the middle Amazon. Verhandlungen des Internationalen Verein Limnologie 25: 1862-1865. 
Kissmann, K.G. 1997. Plantas infestantes e nocivas, Tomo I. 2 ed., BASF, São Paulo.

Kita, K.K. \& Souza, M.C. 2003. Levantamento florístico e fitofisionomia da lagoa Figueira e seu entorno, planície alagável do alto rio Paraná, Porto Rico, Estado do Paraná, Brasil. Acta Scientiarum 25: 145-155.

Longhi-Wagner, H.M., Bittrich, V., Wanderley, M.G.L. \& Shepherd, G.J. (eds.). 2001. Poaceae. In: M.G.L. Wanderley, G.J. Shepherd \& A.M. Giulietti (coords.). Flora Fanerogâmica do Estado de São Paulo, v. 1. Fapesp \& Hucitec, São Paulo.

Lorenzi, H. 2000. Manual de identificação e de controle de plantas daninhas: plantio direto e convencional. 5 ed., Instituto Plantarum, Nova Odessa.

Martinelli, G. \& Moraes, M.A. (orgs.). 2013. Livro Vermelho da Flora do Brasil. Instituto de Pesquisa Jardim Botânico do Rio de Janeiro, Rio de Janeiro.

Martins, C.R., Hay, J.D.V., Valls, J.F.M., Leite, L.L. \& Henriques, R.P.B. 2007. Levantamento das gramíneas exóticas do Parque Nacional de Brasília, Distrito Federal, Brasil. Natureza \& Conservação 5: 23-30.

Michelan, T.S., Thomaz, S.M. \& Bini, L.M. 2013. Native macrophyte density and richness affect the invasiveness of a tropical Poaceae species. Plos One 8: 1-8.

Mormul, R.P., Ferreira, F.A., Michelan, T.S., Carvalho, P., Silveira, M.J. \& Thomaz, S.M. 2010. Aquatic macrophytes in the large, sub-tropical Itaipu Reservoir, Brazil. Revista de Bioliologia Tropical 58: 1437-1452.

Nascimento, M.P.S.C.B. \& Renvoize, S.A. 2001. Gramíneas forrageiras naturais e cultivadas na Região Meio-Norte. EMBRAPA Meio Norte, Teresina \& Royal Botanic Gardens, Kew.

Nunes-da-Cunha, C. \& Junk, W.J. 2011. A preliminary classification of habitats of the Pantanal of Mato Grosso and Mato Grosso do Sul, and its relation to national and international wetland classification systems. In: W.J. Junk, C.J. Silva, C. Nunes-da-Cunha, \& K.M. Wantzen (eds.). The Pantanal: ecology, biodiversity and sustainable management of a large neotropical seasonal wetland. Pensoft Publishers, Sofia-Moscow. pp. 127-141.

Pagotto, M.A., Silveira, R.M.L., Nunes-da-Cunha, C. \& Fantin-Cruz, I. 2011. Distribution of herbaceous species in the soil seed bank of a flood seasonality area, northern Pantanal, Brazil International Review of Hydrobiology 96: 149-163.

Pott, A. 1985. Forrageiras nativas das sub-regiões arenosas do pantanal mato-grossense. In: Anais do $33^{\circ}$ Congresso Nacional de Botânica, Maceió, pp. 11-18.

Pott, A. 1994. Ecossistema Pantanal. In: J.P. Puignau (ed.). Utilización y manejo de pastizales. IICA-PROCISUR, Montividéo, pp. 31-34.

Pott, A. 2000. Dinâmica da vegetação do Pantanal. In: T.C. Cavalcanti \& B.M.T. Walter (orgs.). Tópicos Atuais em Botânica. Embrapa Recursos genéticos e Biotecnologia/ Sociedade Botânica do Brasil, Brasília, pp. 172-182.
Pott, V.J. \& Pott, A. 2000. Plantas aquáticas do Pantanal. EMBRAPA, Brasília.

Pott, A. \& Pott, V.J. 2009. Vegetação do Pantanal: fitogeografia e dinâmica. In: Anais do $2^{\circ}$ Simpósio de Geotecnologias no Pantanal, Corumbá, pp. 1065-1076.

Pott, V.J., Rego, S.C.A. \& Pott, A. 1986. Plantas uliginosas e aquáticas do pantanal arenoso. Embrapa, Pesquisa em andamento 6: 1-12.

Pott, V.J., Bueno, N.C., Pereira, R.A.C., Salis, S.M. \& Vieira, N.L. 1989. Distribuição de macrófitas aquáticas numa lagoa na fazenda Nhumirim, Nhecolândia, Pantanal, MS. Acta Botanica Brasilica 3: 153-168.

Pott, V.J., Bueno, N.C., \& Silva, M.P. 1992. Levantamento florístico e fitossociológico de macrófitas aquáticas em lagoas da Fazenda Leque, Pantanal, MS. In: Anais do $8^{\circ}$ Congresso da Sociedade Botânica de São Paulo, Campinas, pp. 91-99.

Pott, V.J., Cervi, A.C., Bueno, N.C. \& Pott, A. 1999. Dinâmica da vegetação aquática de uma lagoa permanente da fazenda Nhumirim, pantanal da Nhecolândia-MS. In: Anais do $2^{\circ}$ Simpósio Sobre Recursos Naturais e Socioeconômicos do Pantanal Manejo e Conservação, Corumbá, pp. 227-235.

Pott, A., Oliveira, A.K.M., Damasceno-Júnior, G.A. \& Silva, J.S.V. 2011. Plant diversity of the Pantanal wetland. Brazilian Journal of Biology 71: 265-273.

Prado, A.L., Heckman, C.W. \& Martins, F.R. 1994. The seasonal succession of biotic communities in wetlands of the tropical wet-and-dry climatic zone: II. The aquatic macrophyte vegetation in the pantanal of Mato Grosso, Brazil. Internationale Revue der Gesamten Hydrobiologie und Hydrographie 79: 569-589.

Rebellato, L. \& Nunes-da-Cunha, C. 2005. Efeito do "fluxo sazonal mínimo da inundação" sobre a composição e estrutura de um campo inundável no Pantanal de Poconé, MT, Brasil. Acta Botanica Brasilica 19: 789-799.

Rodrigues-da-Silva, R. \& Filgueiras, T.S. 2003. Gramíneas (Poaceae) da Área de Relevante Interesse Ecológico (ARIE) "Santuário de Vida Silvestre do Riacho Fundo", Distrito Federal, Brasil. Acta Botanica Brasilica 17: 467-486.

Santos, L.M., Fernandez, O.V.Q. \& Stevaux, J.C. 1992. Aspectos morfogenéticos das barras de canal do rio Paraná, na região de Porto Rico, PR. Boletim Geografia 10: 11-24.

Shirasuna, R.T., Filgueiras, T.S. \& Barbosa, L.M. 2013. Poaceae do Rodoanel Mario Covas, Trecho Sul, São Paulo, SP, Brasil: florística e potencial de uso na restauração de áreas degradadas. Hoehnea 40: 521-536.

Silva, M.P., Mauro, R., Pott, A., Boock, A., Pott, V. \& Ribeiro, M. 1997. Una sabana tropical inundable: el Pantanal Arcilloso, propuesta de modelos de estados e transiciones. Ecotropicos 10: 87-98. 
Slusarski, S.R. \& Souza, M.C. 2012. Inventário florístico ampliado na mata do Araldo, planície de inundação do alto rio Paraná, Brasil. Revista de Estudos Ambientais 14: 14-27.

Smith, L.B.,Wasshausen, D.C. \& Klein, R.M. 1981. 3. Chusquea. In: R. Reitz (ed.). Flora Ilustrada Catarinense,Gramíneas, part. 1, Herbário "Barbosa Rodrigues", Itajaí, pp. 55-103.

Soderstrom, T.R. \& Young, S.M. 1983. A guide to collecting bamboos. Annals of the Missouri Botanical Garden 70: 128-146.

Soreng, R.J., Peterson, P.M., Romaschenko, K., Davidse, G., Zuloaga, F.O., Judziewicz, E.J. Filgueiras, T.S., Davis, J.I. \& Morrone, O. 2014. A worldwide phylogenetic classification of the Poaceae (Gramineae). Journal of Systematics and Evolution 53: 117-137.

Souza-Filho, E.E. 1994. Feições do Sistema anastomosado pré-atual do rio Paraná. In: Anais do $38^{\circ}$ Congresso Brasileiro de Geologia, Camboriú, 407-409.

Souza, M.C., Cislinski, J. \& Romagnolo, M.B. 1997. Levantamento florístico. In: A.E.A.M. Vazzoler, A.A. Agostinho \& N.S. Hahn (eds.). A planície de inundação do alto Rio Paraná: aspectos físicos, biológicos e socioeconômicos. Editora da Universidade Estadual de Maringá, Maringá, pp. 343-368.

Souza, M.C., Kawakita, K., Slusarski, S.R. \& Pereira, G.F. 2009. Vascular flora of the Upper Paraná River floodplain. Brazilian Journal of Biology 69: 735-745.
Souza, V.C. \& Lorenzi, H. 2008. Botânica sistemática: guia ilustrado para identificação das famílias de fanerógamas nativas e exóticas no Brasil, baseado em APG II. Instituto Plantarum, Nova Odessa.

Stevaux, J.C., Martins, D.P., \& Meurer, M. 2009. Changes in a large regulated tropical river: the Paraná River dowstream from the Porto Primavera Dam, Brazil. Geomorphology 113: 230-238.

Thiers, B. 2015. [continuously updated]. Index Herbariorum: A global directory of public herbaria and associated staff. New York Botanical Garden's Virtual Herbarium. Disponível em http://sweetgum.nybg.org/ $\mathrm{ih} /$ (acesso em 30-VI-2015).

UEM - Universidade Estadual de Maringá. 2015. A planície alagável do Rio Paraná: estrutura e processo ambiental. Nupélia/PELD, Maringá. Disponivel em: http://www.peld. uem.br/ (acesso em 15-VIII-2015).

Watson, L. \& Dallwitz, M.J. 1992. The grass genera of the world: descriptions, illustrations, identification, and information retrieval; including synonyms, morphology, anatomy, physiology, phytochemistry, cytology, classification, pathogens, world and local distribution, and references. Disponível em http://delta-intkey.com (acesso em 18-X-2012).

Worbes, M. 1997. The forest ecosystem of the floodplains. In: W.J. Junk (ed.). The Central Amazon floodplain. Springer, Ecological Studies, Berlin, pp. 223-265. 